DAN MACON, University of California Cooperative Extension (UCCE) Livestock and Natural Resources Advisor, Placer, Nevada, Sutter, and Yuba Counties; ROGER BALDWIN, UCCE Human-Wildlife Conflict

Resolution Specialist, Department of Wildlife, Fish and Conservation Biology, UC Davis; DAVID LILE, UCCE Livestock and Natural Resources Advisor, Lassen County; JEFF STACKHOUSE, UCCE Livestock and Natural Resources Advisor, Humboldt and Del Norte Counties; CARISSA KOOPMANN RIVERS, UCCE Livestock and Natural Resources Advisor, Siskiyou County; TINA SAITONE, UCCE Livestock and Rangeland Economics Specialist, Department of Agricultural and Resource Economics, UC Davis; TRACY SCHOHR, UCCE Livestock and Natural Resources Advisor; LAURA SNELL, UCCE Livestock and Natural Resources Advisor, Modoc County; JOHN HARPER, UCCE Livestock and Natural Resource Advisor, Lake and Mendocino Counties; ROGER INGRAM, UCCE Livestock and Natural Resources Advisor Emeritus (retired), Placer, Nevada, Sutter, and Yuba Counties; KIM RODRIGUES, Director, UCCE Hopland Research and Extension Center; LUKE MACAULAY, UCCE Rangeland Planning and Policy Specialist, Department of Environmental Science, Policy and Management, UC Berkeley; LESLIE ROCHE, UCCE Rangeland Management Specialist, Department of Plant Sciences, UC Davis

\section{Livestock Protection Tools for California Ranchers}

onflicts between livestock and predlators are perhaps inevitable, especially on extensively managed rangelands (Breck 2004). In many parts of North America, large carnivore populations are increasing due to habitat restoration, reintroduction, and legal protection efforts. In many cases, these single-species conservation successes have increased humancarnivore conflicts and highlighted concerns about "whole picture" tradeoffs across multiple-use working landscapes. Public perception and legal restriction of lethal predator control makes knowledge and use of nonlethal livestock protection methods critical for California ranchers. Reducing conflicts between predators and livestock is critical for maintaining

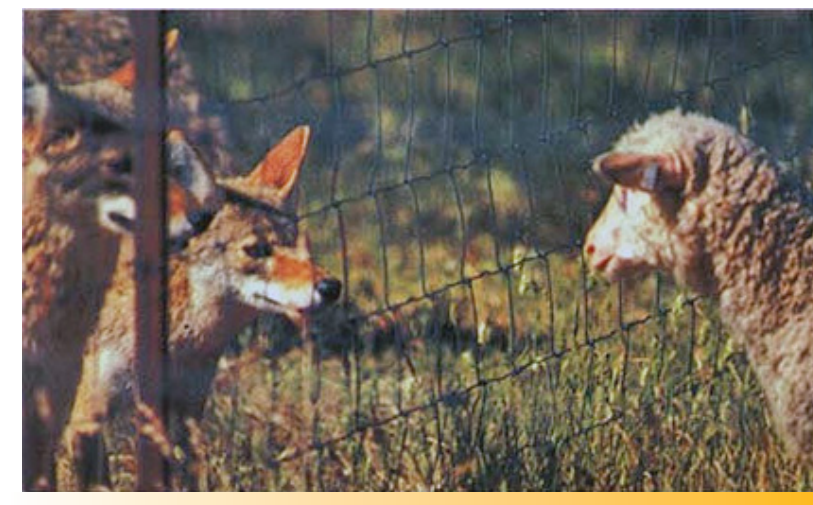

Figure 1. Coyotes can be a significant concern for sheep producers. Photo: California Agriculture. Photo: R. Timm. viable ecosystems and ranching enterprises (Miller et al. 2016). This publication helps producers evaluate livestock protection tools that may fit their site-specific needs. Much of the research on nonlethal livestock protection tools has been conducted outside California. In addition, experimental studies (as opposed to surveys) regarding the efficacy of nonlethal tools are rare (Eklund et al. 2017). Future research may adapt these tools to California-specific conditions and predators. 


\section{Predators of Concern}

Many large predators depend on rangeland habitats in California, most notably coyotes (Canis latrans), black bears (Ursus americanus), and mountain lions (Puma concolor). The preferred habitat of the recently returned gray wolf (Canis lupus) also encompasses rangeland habitats in northern California as it does in other western states (CDFW 2016). Smaller predators, including foxes (Vulpes vulpes) and bobcats (Lynx rufus) can be problematic for sheep and goat producers. Additionally, domestic dogs may be the predator of greatest concern in some regions (Young et al. 2011). Nationally, in 2014, dogs caused $21.4 \%$ of predator losses in adult sheep and $10.3 \%$ of predator losses in lambs (USDA-APHIS 2015). Anecdotally, California producers report an increase in feral dogs associated with illegal marijuana production in some regions. Finally, while this publication focuses on mammalian predators, sheep and goat producers (and some cattle producers) may suffer localized predation from raptors (primarily golden and bald eagles) and scavenger birds (crows and magpies).

The California Department of Fish and Wildlife (CDFW) is responsible for managing the state's wildlife resources. Some of these predators are subject to the state's game laws (for example, black bears are managed as a game species subject to licensing

Figure 2. In addition to providing forage for livestock, California wildlands provide habitat for mountain lions. Photo: CDFW.

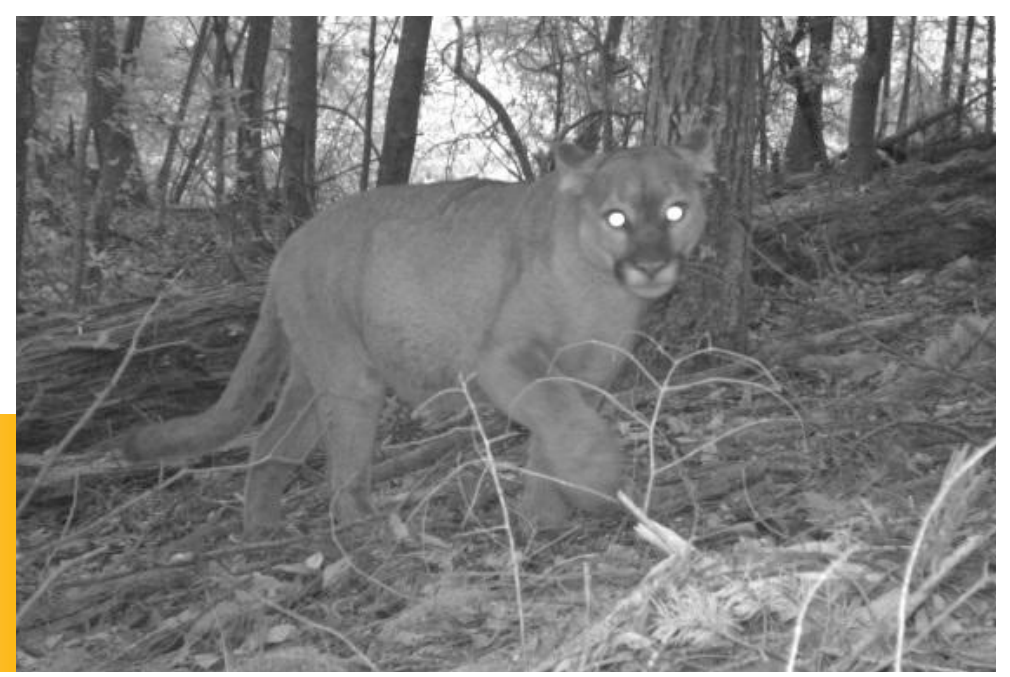

requirements, bag limits, and harvest quotas). Some, like the mountain lion, have special protected status via state ballot initiative; it is illegal to kill a mountain lion without a depredation permit issued by CDFW. Gray wolves are protected by the California and federal endangered species acts (CESA and ESA, respectively). Under the provisions of state and federal endangered species laws, it is currently illegal to use lethal control of wolves under any circumstance in California.

\section{Predator Impacts}

The killing of livestock by predators represents a direct economic loss to ranchers. These direct losses can be quantified using current market prices; however, indirect losses pose greater complexity in assessing the total cost of predator impacts to ranchers. Current research suggests that indirect losses (such as reduced weight gain, reduced reproductive success, and additional labor) may be more substantial than direct predator losses (Ramler et al. 2014). In addition, the loss of an individual animal also represents the loss of that animal's future genetic potential in a particular herd or flock, as well as the loss of years of investment by the rancher (NaughtonTreves et al. 2003).

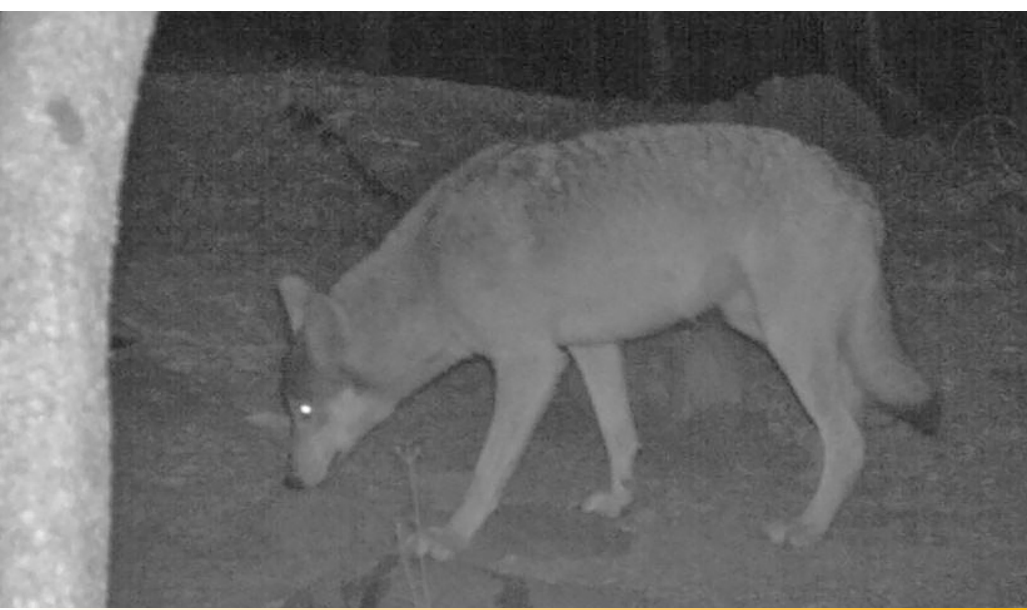

Figure 3. Gray wolves have recently returned to California. Photo: CDFW. 
Livestock depredation is an emotional issue for ranchers, intertwined with their sense of stewardship and responsible animal husbandry. On the other hand, lethal control of predators is often a contentious issue for the public. While cattle death losses from predators are generally less than losses from other sources (including disease and old age), localized predator impacts can be severe. Not surprisingly, sheep producers typically experience greater impacts from predation. While just $1 \%$ of reported death losses of mature cattle in California in 2015 were attributed to predators, 19\% of reported death losses in mature sheep in 2014 were caused by predators (table 1). Similarly, while approximately $6 \%$ of reported calf losses in 2015 were due to predators, over $45 \%$ of lamb losses were predator-caused.

\section{The Livestock Protection Toolbox}

Coexisting with predators requires an integrated approach: a combination of predator protection tools, adaptive management, and situational awareness. Livestock protection tools can alter human behavior, alter livestock husbandry practices, alter predator behavior and/or provide disruptive or aversive stimuli to predators (Shivik 2004). Producer selection of specific nonlethal tools depends on efficacy, cost-benefit considerations, public perceptions (including market forces that may increase demand for predator coexistence), and producer attitudes toward and confidence in the methods. Additionally, individual producer perspectives and site-specific conditions often influence adoption and success. Ultimately, if a producer does not think these tools will work, it may be difficult to convince them otherwise. Similarly, if a producer thinks these tools will work, a setback will likely not change their mind. Recent research suggests that these tools must be applied preemptively (i.e., before predation occurs), site-specifically, and in combination to maximize effectiveness (Stone et al. 2017). While there is no consensus as to which tools are most effective and under what circumstances these tools may work (Miller et al. 2016; Eklund et al. 2017), the most appropriate tool likely depends on a variety of factors, including type and size of operation (extensive rangeland, irrigated pasture, etc.), predator and livestock behavior, tool efficacy and cost-benefit ratio, and producer commitment and experience. In other words, the effectiveness of these nonlethal tools depend on context and the accuracy with which the specific problem predator is targeted (Eklund et al. 2017).

\section{Lethal Control}

In some cases, selective targeted lethal control-in which a predator known to be responsible for a specific predation event is killedmay be the most appropriate and cost-effective tool if permitted by law. Existing information indicates targeted lethal removal of some predators (especially coyotes and wolves) is primarily effective at the ranch or watershed scale but may have little effect at the county or regional scale (Conner et al. 1998; Knowlton et al. 1999; Blejwas et al. 2002; CDFW 2016). Non-targeted lethal control can be an expedient approach with some short-term benefits (Wagner and Conover 1999; Treves and Ullas Karanth 2003); however,

Table 1. Death losses by cause for cattle and sheep in California

\begin{tabular}{|l|c|c|c|c|}
\hline & \multicolumn{2}{|c|}{ Beef cattle (2015) } & \multicolumn{2}{c|}{ Sheep (2014) } \\
\hline Death losses by cause & $\#$ & $\%$ & $\#$ & \% \\
\hline death losses from predators, mature animals & 1,103 & 1.1 & 2,277 & 19.0 \\
\hline nonpredator losses, mature animals & 98,897 & 98.9 & 9,723 & 81.0 \\
\hline death losses from predators, calves and lambs & 8,178 & 5.8 & 3,171 & 45.3 \\
\hline nonpredator death losses, calves and lambs & 131,822 & 94.2 & 3,829 & 54.7 \\
\hline
\end{tabular}


some research indicates indiscriminant lethal control of carnivore populations may not have lasting effects (Conner et al. 1998; Knowlton et al. 1999; Wielgus and Peebles 2014). Finally, targeted lethal control may enhance the effectiveness of certain nonlethal tools and may increase tolerance for the presence of some predators (Bangs et al. 2006)

\section{Non-Lethal Protection Methods}

USDA-APHIS found only 20 percent of U.S. beef cattle operations used nonlethal predator protection tools in 2015 (USDA-APHIS 2016). Small ruminant producers, who generally face greater predation risks than beef producers, make greater use of these tools - in 2014, 58\% and 93\% of sheep and goat operations, respectively, used one or more nonlethal tools (USDA-APHIS 2014). Table 2 summarizes types and combinations of tools used by beef cattle, sheep, and goat producers.

Success of nonlethal protection tools may be measured on a gradient from reduction to total elimination of predation. Most of the current information on nonlethal tools has been conducted via producer surveys, with limited published experimental data. While Eklund et al. (2017) and others have focused on analyzing peer-reviewed literature, we have included observations and analysis from scientific studies as well as credible, on-the-ground experience. Therefore, Table 3 combines existing experimental research with field-based information (including Shivik 2004; Bangs et al. 2006; Eklund et al. 2017; Stone et al. 2017). This table is intended to assist producers in evaluating a suite of nonlethal tools that may fit their particular operations. Site-specific conditions (like topography, vegetative cover, and other factors) should also be considered.

Below, we review a number of the most frequently used nonlethal predator protection tools. Optimal strategies for protecting livestock may include baseline preventative husbandry techniques (livestock guardian animals and electric fencing, for example) supplemented with deterrents (fladry or sound-light devices) during key production periods (Miller et al. 2016).

\section{Livestock Guardian Animals}

Livestock producers have used guarding animals to protect flocks and herds for thousands of years. Guardian animals are frequently used in sheep and goat operations (Coppinger et al. 1988; Gehring et al. 2011; VanBommel and Johnson 2013; USDA-APHIS 2015).

Beef cattle operations, generally, are less likely to employ guardian animals, although some ranchers in the northern Rocky Mountains and upper Midwest have used livestock guardian dogs to successfully protect cattle from gray wolves (USDA-APHIS 2010; Gehring et al. 2010). The benefits of using livestock guardian animals include decreases in or elimination of predation, reduced labor (relative to

Table 2. Top five nonlethal livestock protection tools (or combination of tools) used by beef cattle, sheep, and goat producers in the United States

\begin{tabular}{|c|c|c|c|c|c|}
\hline \multicolumn{2}{|c|}{$\begin{array}{l}\text { Beef cattle producers, } 2016 \\
\text { (20\% used any nonlethal tool) \% }\end{array}$} & \multicolumn{2}{|c|}{$\begin{array}{l}\text { Sheep producers, } 2014 \\
\text { (58\% used any nonlethal tool) \% }\end{array}$} & \multicolumn{2}{|c|}{$\begin{array}{l}\text { Goat producers, } 2014 \\
\text { (93\% used any nonlethal tool) \% }\end{array}$} \\
\hline guard animals only & 26.3 & fencing only & 14.3 & other nonlethal & 22.8 \\
\hline fencing only & 15.5 & guard dogs only & 9.0 & fencing only & 12.5 \\
\hline other nonlethal & 5.1 & fencing and guard dogs & 6.0 & guard dogs only & 6.2 \\
\hline frequent checks only & 5.1 & night penning only & 3.4 & guard dogs and fencing & 3.9 \\
\hline guard animals and fencing & 4.1 & guard donkeys only & 2.7 & fencing and other nonlethal & 3.1 \\
\hline
\end{tabular}


Table 3. Tool selection guidelines for predators of concern

\begin{tabular}{|c|c|c|c|c|c|c|c|}
\hline Tool & Dog & Coyote & $\begin{array}{l}\text { Mountain } \\
\text { Lion }\end{array}$ & $\begin{array}{l}\text { Black } \\
\text { bear }\end{array}$ & $\begin{array}{l}\text { Gray } \\
\text { wolf }\end{array}$ & Fox & Bobcat \\
\hline Livestock guardian dog & $\bullet$ & $\bullet$ & $\bullet$ & $\bullet$ & $\bigcirc$ & $\bullet$ & $\bullet$ \\
\hline Donkey & $\bullet$ & $\bullet$ & NA & NA & NA & $\bullet$ & NA \\
\hline Llama & $\bullet$ & O & NA & NA & NA & O & NA \\
\hline Woven-wire fencing with trip wire & $\bullet$ & $\bullet$ & NA & NA & NA & NA & NA \\
\hline Permanent electric fencing & $\bullet$ & $\bullet$ & O & $?$ & O & $\bullet$ & $\bullet$ \\
\hline Temporary electric fencing & $\bullet$ & $\bullet$ & $?$ & NA & O & $\bullet$ & $\bullet$ \\
\hline Electro-net fencing & $\bullet$ & $\bullet$ & NA & NA & NA & $\bullet$ & $\bullet$ \\
\hline Fladry or turbo fladry & NA & $?$ & NA & NA & O & NA & NA \\
\hline Attractant (carcass) removal & $\bullet$ & $\bullet$ & $\bullet$ & $\bullet$ & $\bullet$ & $\bullet$ & $\bullet$ \\
\hline Human presence or stockmanship & NA & NA & NA & NA & $\mathrm{O}$ & NA & NA \\
\hline Night pen (small-scale operations) & NA & $\bullet$ & $\bullet$ & $\bullet$ & $\bullet$ & $\bullet$ & $\bullet$ \\
\hline Fright tactics or devices & & $?$ & $?$ & $?$ & $?$ & $?$ & $?$ \\
\hline Shed lambing, calving, or kidding & $\bullet$ & $\bullet$ & $\bullet$ & $\bullet$ & $\bullet$ & $\bullet$ & $\bullet$ \\
\hline Multispecies grazing (cattle with small ruminants) & 0 & 0 & $?$ & $?$ & $?$ & O & $?$ \\
\hline
\end{tabular}

Key: $\bullet$ = Highly effective; $O=$ Moderately effective; ? = Research results with varying effectiveness; $N A=$ No available evidence. night penning or range riding), more efficient use of pastures (that is, livestock can safely graze in the presence of predators) (Webber et al. 2015), and greater peace of mind for producers. Guard animal effectiveness is influenced by a variety of factors and their use requires a commitment by their owners (Andelt 2004). Cost of acquisition of livestock guardian animals is highly variable.

Dogs, donkeys, and llamas are most commonly used. Dogs appear to be the most effective option for protecting livestock from the full range of predators present in California (Gehring et al. 2010). Donkeys and llamas, on the other hand, may be longer lived than dogs and easier to maintain given that their dietary requirements overlap with livestock (Walton and Field 1989; Andelt
2004; Franklin and Powell 2006). However, donkeys and llamas are not as effective when protecting livestock from mountain lions, bears, or gray wolves (Wilbanks 1995). Ultimately, producers should remember that donkeys and llamas, like the livestock they are guarding, are prey animals.

\section{Livestock guardian dogs}

Livestock guardian dog breeds were developed through selective breeding in Europe and Asia to protect livestock from bears and wolves (Andelt 2004). Common breeds in North America include Great Pyrenees (originally from France), Anatolian Shepherd and Akbash (from Turkey), Komondor (from Hungary), and Maremma (from Italy) (USDA-APHIS 2010). Due to increased predation from gray wolves and grizzly bears in the Northern Rocky Mountains, USDA Wildlife Services is currently investigating additional breeds-including Kangal (from Turkey), Karakachan (from Bulgaria), and Cao de Gado Transmontaño (from Portugal) - for protective capabilities and docility towards humans (USDA-APHIS 2014). Several studies suggest that livestock guardian dogs lower the risk of sheep predation (Eklund et al. 2017).

Livestock guardian dogs disrupt predatory behavior rather than displace predators, such that predators likely remain present and continue to prey on other wildlife species. While further study is necessary, this suggests that guardian dog use does not result in increased predator pressure on neighboring operations that do not use dogs (Coppinger et al. 1988). Livestock protection behaviors must be induced or enhanced at some level by appropriate rearing conditions, training, and management. Proper rearing of livestock guardian dog puppies is critical; improperly reared dogs cannot be retrained to become successful guardians. Similarly, dogs that come from working (as opposed to pet) lines generally make better guardians. Producers should utilize the natural genetic and behavioral variations in these 


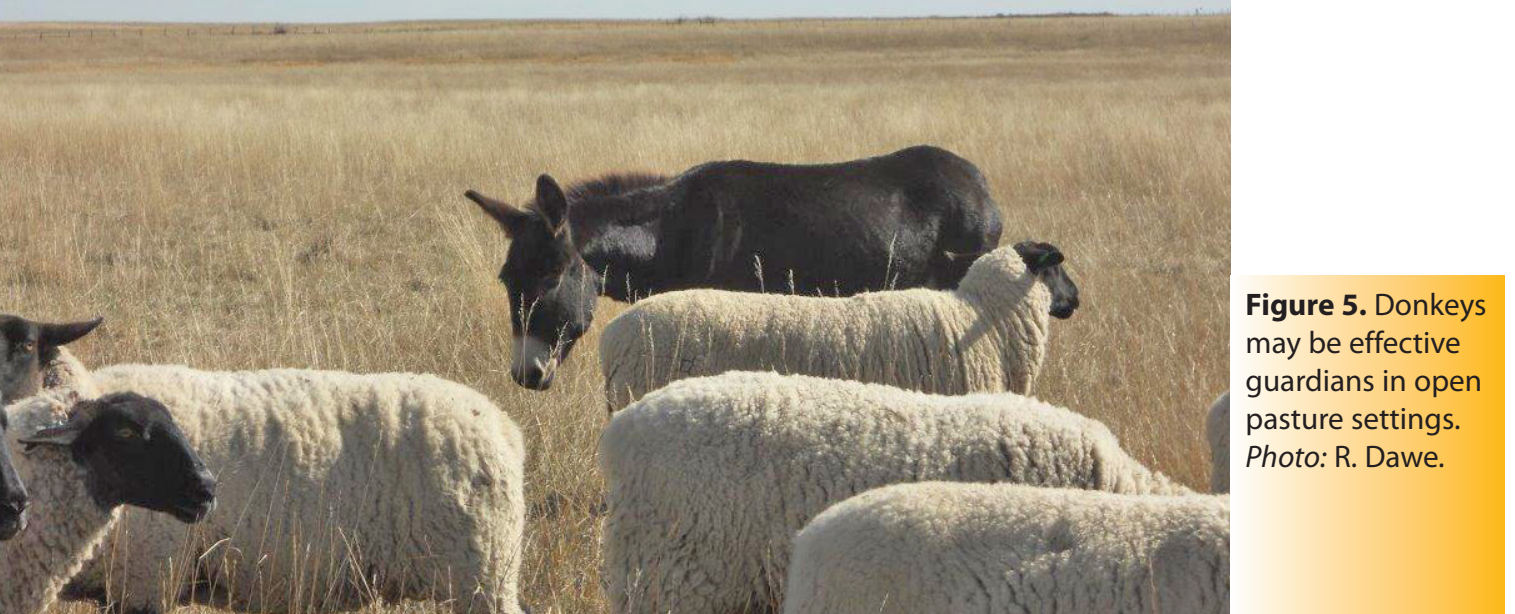

towards livestock, and females in heat may be aggressive towards lambs or kids. Donkeys should be removed from livestock during lambing or kidding because they may disrupt maternal bonding. Donkeys will also bond with other donkeys and equines in adjacent pastures, rather than with the target livestock. Donkeys must not be given access to feeds with ruminant-only feed additives (like Rumensin and other ionophores), which are extremely toxic to all equines (Walton and Field 1989). Additionally, donkeys cannot digest woody forage and therefore require alternative feed sources or supplemental feeding if they are guarding sheep or goats in brush control projects.

Llamas

Llamas are South American camelids (a family that includes the domesticated alpaca and the wild guanaco and vicuna). The wild members of the camelid family will chase foxes and flee from mountain lions (Franklin and Powell 2006); similarly, some llamas are naturally aggressive towards dogs and coyotes (Andelt 2004). Typical guarding behaviors include alertness; alarm calling; walking or running toward a predator; chasing, kicking or pawing at a predator; spitting; herding livestock away from a predator; or placing themselves between livestock and a predator. Like donkeys, llamas have similar dietary and management requirements to the livestock they protect. Leadership, alertness, and weight seem to be correlated with aggressiveness. In other words, large and alert llamas make the best guardians (Cavalcanti and Knowlton 1998).

While the research on llamas as livestock guardians is somewhat limited, some literature suggests that llamas can effectively deter dogs, coyotes, and foxes, but not wolves, bears, or mountain lions (Wilbanks 1995). Llamas seem to work best in small- to mid-sized operations (for example, 250-300 sheep or goats in pastures of 250-300 acres). Llamas apparently do not require training to stay with sheep, and single llamas seem to work better than multiple llamas (i.e., they may bond to each other rather than to the livestock they are guarding) (Franklin and Powell 2006).

\section{Fencing}

Humans began using barrier fences to protect themselves and their livestock from predators in prehistoric times (Wade 1982). Modern livestock producers often use fencing to enclose livestock, exclude

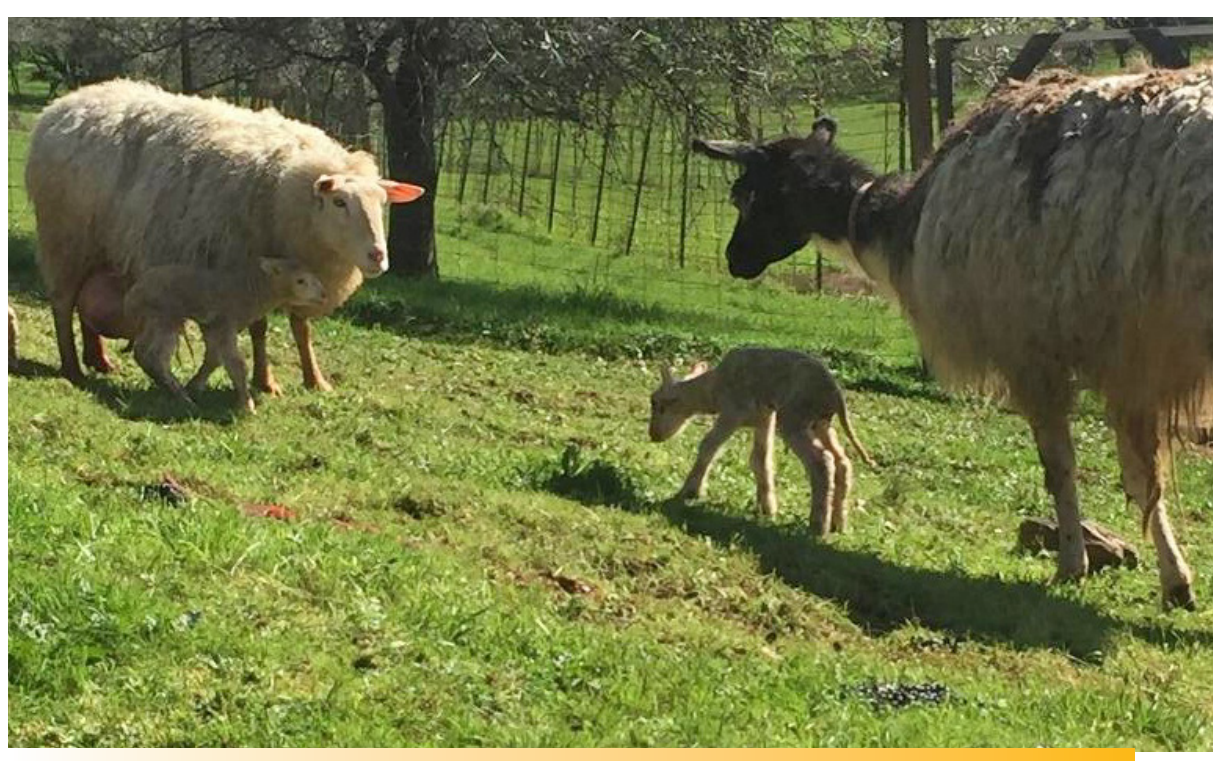

Figure 6. Llamas can provide protection in smaller-scale settings. Since llamas and donkeys share dietary requirements with the livestock they protect, operating costs (including labor) may be lower than for livestock guardian dogs. Photo: $\mathrm{C}$. McDonald. 
predators, or both. Fences can be categorized as physical barriers, psychological barriers (e.g., by inflicting a shock or other painful stimulus), or a combination of the two.

Topography, habitat type, pasture size, wild ungulate populations, livestock type, and predator type all influence the effectiveness of fencing. Regulatory restrictions on type of fencing (for example, the use of smooth wire to facilitate deer or antelope passage on public land) may limit fence effectiveness for predation prevention. In addition to construction and maintenance costs, confining livestock within a predator-proof fence may incur additional production costs, including inefficient use of forage resources, problems with livestock disease control, reductions in wool or mohair quality, and increased labor (Wilbanks 1995). Fencing as a stand-alone predator protection tool seems to be most useful and cost-effective on small, level, and relatively open pastures. Most of the existing literature appears to evaluate effectiveness of fencing in preventing coyote and dog predation (Thompson 1976; Gates et al. 1978; Wade 1982; Acorn and Dorrance 1994). Little if any fencing research has evaluated effectiveness in preventing predation from wolves, mountain lions or bears.

\section{Permanent Hard-Wire Fencing (Physical Barrier)}

Conventional 5- or 6-strand barbed wire fences may be effective at containing some livestock (cattle in particular) but are not effective predator barriers. Many producers use permanent steelwire net fences, augmented by barbed or electrified wires above the net fencing, and occasionally by an electrified trip wire just above ground level on the outside of the net fencing. An adult coyote can squeeze through a 4-by-6 inch opening in woven wire, and can climb or jump fences that are less than 66 inches in height (Thompson 1976). To be a more effective predator deterrent, conventional woven wire fencing should have electrified top and trip wires (Gates et al. 1978; Acorn and Dorrance 1994).

Permanent Electric Fencing (Psychological and/or Physical Barrier) Researchers have evaluated a number of configurations of permanent electric fencing. Research from the late 1970s indicates that a 12-wire fence with alternating grounded and electrified wires and an offset electrified trip wire on the outside of the fence is "coyote proof" (Gates et al. 1978). Maintenance of permanent electric fences is the key to continued effectiveness (Wade 1982). Dry soil conditions (combined with improper fence installation), grounding of the fence on vegetation or on itself, and poor construction (especially the fence grounding system) contribute to the failure of electric fences (permanent and temporary alike).

Temporary Electric Fencing (Psychological and/or Physical Barrier) Temporary electric fences are increasingly utilized to control grazing on crop residues and rented, unfenced land (Ontario Ministry of Agriculture 2016). In some cases, these fences may be effective at protecting livestock from predators as well. Temporary electric fences consist of one or more strands of poly-wire or tape woven with steel wire for electrical conductivity. Several manufacturers make an electrified netting fence (36-48 inches height) in which the horizontal poly-wires may be electrified or alternating hot and grounded. While temporary electric fencing systems typically have a shorter expected life (5 to 7 years) compared to permanent fencing (Ontario Ministry of Agriculture 2016), the initial capital cost is significantly lower. These fences can be energized with portable, battery-powered (and solar charged) low-impedance energizers that deliver a powerful shock (as high as $10 \mathrm{kV}$ ). Temporary fences can be configured similarly to the high-tensile electric fences described above to provide predator protection. More frequently, producers utilize electrified netting for predator protection (especially for sheep and goats). Electrified netting has been shown to reduce coyote intrusions from $47 \%$ to $6 \%$ (Matchett et al. 2013).

Fladry and Turbo (Electrified) Fladry (Psychological Barrier) Fladry is a series of cloth or plastic flags attached to a rope or wire that creates a novel visual stimulus wolves find uniquely frightening (Bangs et al. 2006). Studies in several regions have reported that fladry deters wolves (Musiani et al. 2003; Davidson-Nelson and Gehring 2010); however, over time, wolves have been found to become habituated to fladry, willingly crossing fladry barriers to kill livestock (Musiani et al. 2003). Musiani et al. also found that 


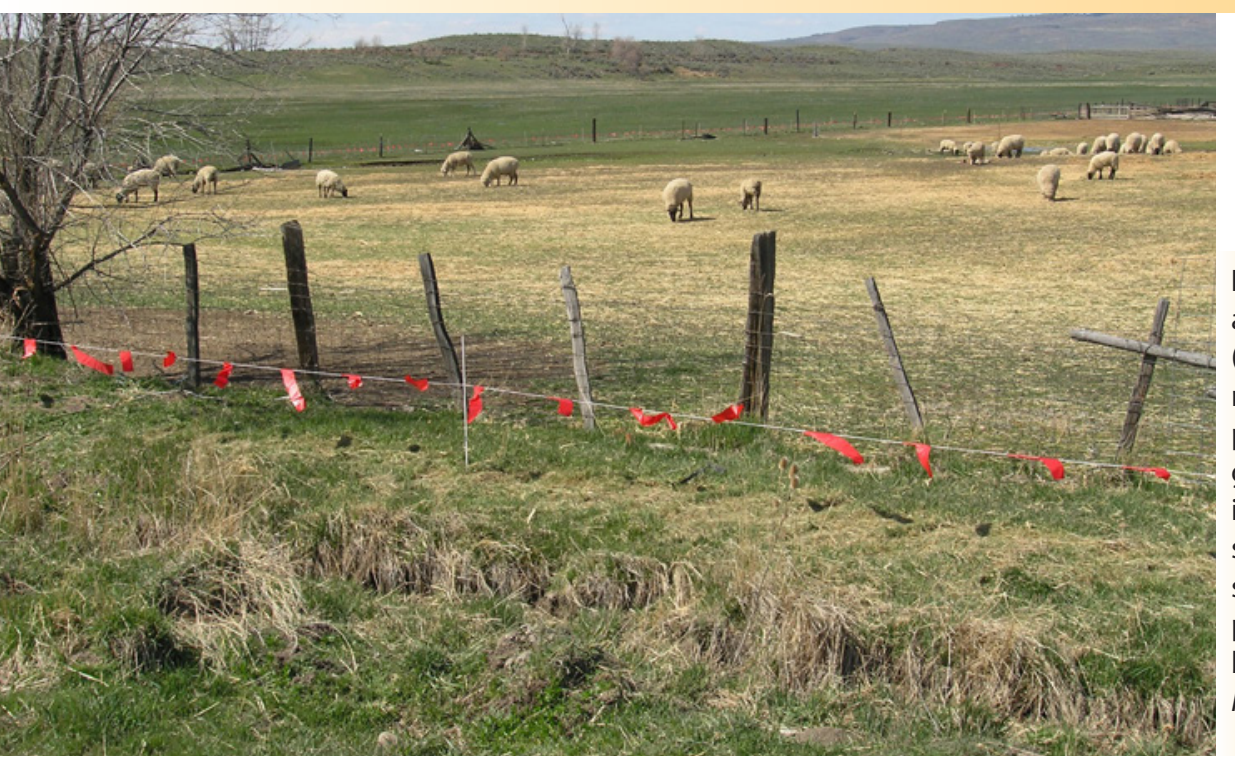

Figure 7. Fladry and turbo-fladry (which is electrified) may provide protection from gray wolves. Fladry is typically used in specific settings such as calving pastures or sheep bedding grounds. Photo: J. Williams.

Figure 8. Electronet fencing can be highly effective at protecting livestock from feral dogs, coyotes, and other small- to mid-size canine predators. Photo: E. Macon. fladry may push wolves to neighboring ranches or unprotected pastures. Turbo fladry (electrified with a standard electric fence energizer) may be as much as 2 to 10 times more effective than nonelectrified barriers (Lance et al. 2010). However, hunger increases the likelihood that a wolf will test any fladry barrier. New designs that reduce or eliminate coiling of flags improve effectiveness and reduce maintenance (Young et al. 2015a). Fladry may be a useful tool in smaller-scale pasture settings (e.g., heifer calving pastures or sheep bedding grounds), but are not particularly useful or effective on large-scale grazing allotments (Parks 2015). Fladry may not be an effective deterrent for predators other than wolves (DavidsonNelson and Gehring 2010), although one study has suggested fladry may deter coyotes as well (Young et al. 2015a).

\section{Attractant Removal}

Most predators are also opportunistic scavengers; therefore, a dead animal may attract predators into an area currently being grazed by livestock. Attractant removal involves the removal and disposal of dead livestock, as well as the removal of sick or injured livestock. These strategies can reduce attraction to areas used by livestock and may avoid giving predators a taste for livestock (Wilbanks 1995). Observational evidence in the northern Rocky Mountains and on the Modoc Plateau suggests wolves that are attracted to bone yards may be more likely to kill cattle or sheep in adjacent areas ( $\mathrm{T}$. Kaminski, pers. comm., 2016). Bone yards may also attract livestock guardian dogs away from the livestock they are protecting (N. East, pers. comm., 2016)

Attractant removal presents several logistical and legal challenges. In remote, extensive rangeland settings, ranchers may have difficulty finding or removing carcasses before they attract scavengers and predators (Parks 2015). In addition, burying livestock carcasses is currently legally prohibited in California (Antonelli et al. 2016), as is the compositing of mammalian flesh (CalRecycle 2017). Carcass recovery and transport to a rendering facility may be cost prohibitive. In light of these limitations, producers should consider moving a carcass as far away from livestock as possible (especially outside any exclusionary fencing). 
Potential solutions may include regulatory changes that would permit the proper burial of livestock in rangeland settings or disposal at landfill facilities. Finally, while sick or injured animals may attract predators, facilities for isolating or loading single animals are typically not available in extensive rangeland settings.

\section{Human Presence and Stockmanship}

In some situations, human presence has been shown to deter predation. Additionally, active hazing with less-than-lethal munitions may modify carnivore hunting patterns and dietary preferences (Bangs et al. 2006). We should note that in California, the use of less-than-lethal munitions on some species (notably wolves) is not permitted. Many large-scale open-range sheep and goat operations in the western United States use herders to manage their day-to-day grazing operations. These herders are typically on site with flocks 24 hours per day, 7 days per week. In 2014, $34 \%$ of large-scale sheep operations (greater than 1,000 head) that used nonlethal tools reported using herders (USDA-APHIS 2015). Within all sheep operations, just over 6\% used herders (see table 2). More than half of the large-scale sheep producers who use herders indicated they checked sheep more frequently when they were in high predation areas or seasons (USDA-APHIS 2015).

Nearly one-third of U.S. sheep production is managed using guest worker $(\mathrm{H}-2 \mathrm{~A})$ herders, most of whom come from Peru or Bolivia; therefore, changes in U.S. immigration policy may affect access to herders (American Sheep Industry 2015).

Individual ranchers, rancher associations, or nonprofit organizations may employ range riders. Range riders have mostly been deployed in areas with potential wolf-livestock conflicts, often with the specific task of disrupting predatory behavior. It has also been suggested that low-stress stockmanship techniques can reinstill herd instinct in cattle. While there is little empirical evidence regarding their effectiveness, ranchers perceive the benefits of range rider programs to include depredation mitigation, increased management and information on livestock, rapid carcass identification, and a variety of social benefits (including reduced stress, reduced trespassing and littering, improved public perception, and trust building). Range riders can also provide additional tools beyond simply being present on the landscape, including carcass removal, treatment of injured or sick animals, and stockmanship (Parks 2015). Wolves, especially, may become habituated to seeing humans, avoiding areas where they see humans during daylight hours and returning at night (Parks 2015; J. Williams, pers. comm. 2016). Varying the pattern of human presence appears to be critical to preventing habituation. Finally, range rider programs may be cost-prohibitive in the long term. Most existing range rider programs are funded through a combination of grant funding (from nonprofit organizations and/ or government agencies) and in-kind contributions from ranchers (e.g., housing, horses or ATVs, investment of time, etc.). Ranchers who have participated in range rider programs in the northern Rocky Mountains perceive the costs to outweigh the benefits (Parks and Messmer 2016).

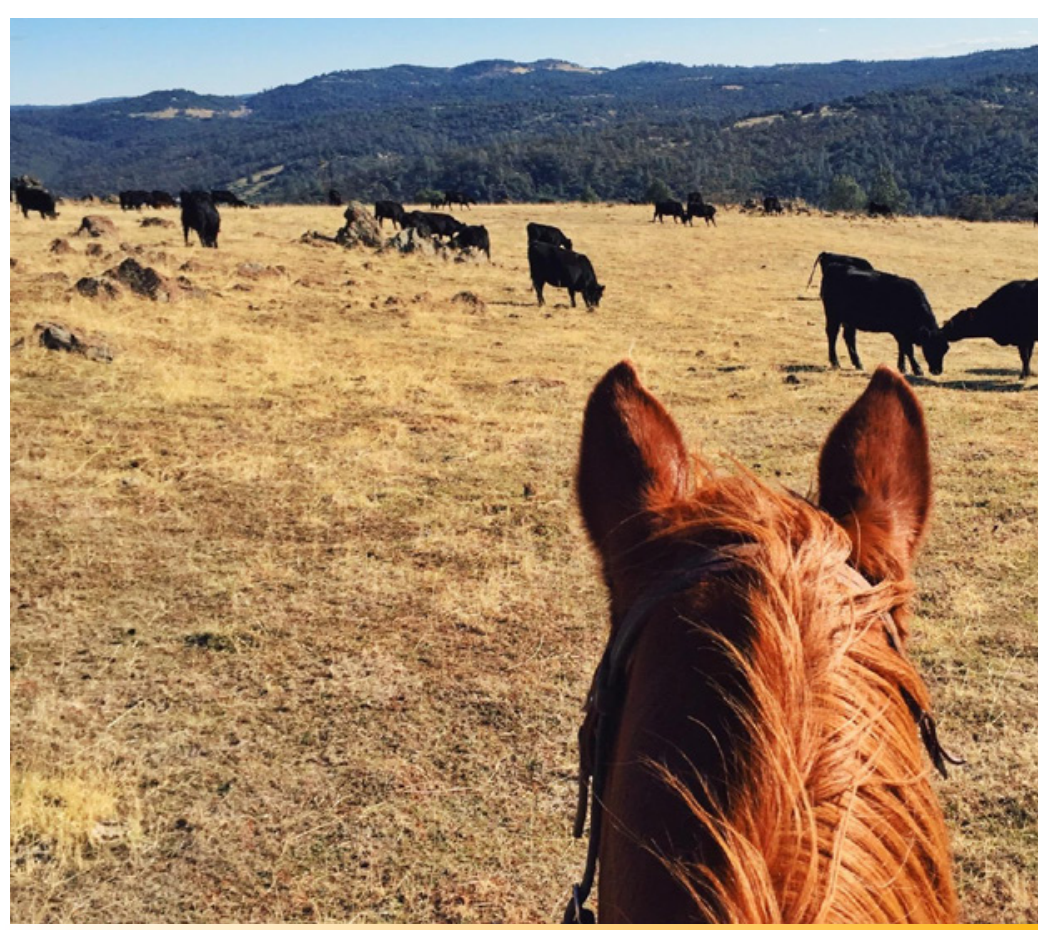

Figure 9. Range riders can increase the efficacy of other nonlethal tools by facilitating timely carcass removal and increasing human presence on rangelands. Photo: L. Macon 


\section{Fright Tactics and Devices}

Some predators are afraid of novel stimuli. Strobe lights, propane cannons, and siren devices (including radio- and motion-activated guard devices) may temporarily displace or confuse predators (Bangs et al. 2006). Early research into battery-operated strobe or siren devices in fenced-pasture sheep operations across the western United States found that these devices deterred coyotes for up to 91 days and reduced lamb losses an estimated 44 to 95\% (Linhart 1984; Linhart et al. 1992). However, habituation can be a problem if these devices are randomly-rather than behaviorally-activated (Shivik and Martin 2001). On the other hand, preliminary research at the University of California Hopland Research and Extension Center (Mendocino County) indicated mixed results with a new type of strobe light that emits random patterns of flashing light (trademarked as FoxLights). While initial results suggest FoxLights may be effective in deterring fox predation, the data do not support hypotheses of reduced livestock predation by coyotes, black bears, or mountain lions (McInturff et al. 2016).

\section{Husbandry and Management Changes}

Specific animal husbandry techniques and management or production systems may reduce livestock-predator conflicts. These systems may include changes in production calendars, management measures that modify livestock behavior, avoidance of predator habitat, and other protective measures.

On the ground, many of these tools are used in combination. Fall birthing seasons may avoid the period of greatest food demand for coyotes (such as springtime, when coyotes are raising their young). Additionally, physically moving lambing or calving away from known wolf dens decreases predation risk. Shed lambing (or calving) also offers protection during a critical production stage. Night penning (and to a lesser extent, simply night gathering) sheep can be effective in reducing wolf predation, especially when used in conjunction with livestock guardian dogs and/or human presence (Espuno et al. 2004). While night penning can provide protection during vulnerable periods, it comes at the cost of additional labor and facility construction and maintenance (Wilbanks 1995). Finally, in certain settings, bonding sheep and goats to cattle in extensive rangeland settings can also provide protection from some predators (Anderson et al. 1987).

\section{Conclusion}

While direct economic losses to predators may be less than those associated with disease and other factors, localized impacts can be significant. Furthermore, emerging work is demonstrating potentially significant indirect impacts on rangeland livestock production due to predators, impacts such as reduced reproductive rates, reduced weaning weights, and increased labor costs. Given the overlap between predator habitat and rangeland livestock production, conflicts are inevitable. While there are no "silver bullets" in terms of livestock protection tools (Breck 2011), siteand operation-specific combinations of these tools may help prevent direct losses and indirect impacts in some production systems (Stone et al. 2017). Specific management practices must be technically effective, economically beneficial, and socially and legally acceptable (Young et al. 2015b; Miller et al. 2016). Producers should evaluate the costs and benefits of these tools in the context of their own operations and in light of their specific experience and expertise. Obviously, every livestock operation is unique and faces challenges based on rancher experience and perspective. Livestock protection tools must be modified from one operation to another and numerous tools be employed simultaneously to reduce livestock losses to predation.

\section{References}

Acorn, R., and M. Dorrance. 1994. An evaluation of anti-coyote electric fences. Proceedings of the 16th Vertebrate Pest Conference. Journal of Range Management 33(5): 385-387.

American Sheep Industry. 2015. Special procedures: Labor certification process for sheepherders and goatherds under the H-2A Program. U.S. Department of Labor, Employment and Training Administration Advisory System, Office of Foreign Labor Certification. Field Memorandum 24-01. 
Andelt, W. 2004. Use of livestock guarding dogs for reducing predation on domestic sheep. Wildlife Society Bulletin 20:55-62.

Anderson, D., et al. 1987. Bonding of young sheep to heifers. Applied Animal Behaviour Science 19:1-2.

Antonelli, S., et al. 2016. An analysis of wolf-livestock conflict hotspots and conflict reduction strategies in northern California. Defenders of Wildlife and Bren School of Environmental Science and Management.

Bangs, E., et al. 2006. Non-lethal and lethal tools to manage wolf-livestock conflict in the northwestern United Sates. In R. Timm and J. O'Brien, eds., Proceedings of the 22nd Vertebrate Pest Conference. Davis: University of California, Davis.

Blejwas, K., et al. 2002. The effectiveness of selective removal of breeding coyotes in reducing sheep predation. Journal of Wildlife Management 62(2): 451-462.

Braithwait, J. 1996. Using guard animals to protect livestock. Jefferson City: Conservation Commission of the State of Missouri.

Breck S. 2004. Minimizing carnivore-livestock conflict: The importance and process of research in the search for coexistence. In N. Fascione, et al., eds., People and predators: From conflict to coexistence. Washington, DC: Island Press. 13-27.

Breck, S., et al. 2011. Domestic calf mortality and producer detection rates in the Mexican wolf recovery area: Implications for livestock management and carnivore compensation schemes. Biological Conservation 144:930-936.

CalRecycle (California Department of Resources Recycling and Recovery). 2017. Compostable materials handling operations and facilities regulatory requirements. CalRecycle website, http://www.calrecycle.ca.gov/SWFacilities/Permitting/ facilitytype/compost.

Cavalcanti, S., and F. Knowlton. 1998. Evaluation of physical and behavioral traits of llamas associated with aggressiveness toward sheep-threatening canids. Applied Animal Behaviour Science 61(2): 143-158.
CDFW (California Department of Fish and Wildlife). 2016. Final conservation plan for gray wolves in California. CDFW website, https://www.wildlife.ca.gov/conservation/mammals/ gray-wolf.

Conner, M., et al. 1998. Impact of coyote removal on sheep depredation in northern California. Journal of Wildlife Management 62:690-699.

Coppinger, R., et al. 1988. A decade of using livestock-guarding dogs. In R. Timm, ed., Proceedings of the 13th Vertebrate Pest Conference. Davis: University of California, Davis. 209-214.

Davidson-Nelson, S., and T. Gehring. 2010. Testing fladry as a nonlethal management tool for wolves and coyotes in Michigan. Human-Wildlife Interactions 4(1): 87-94.

Eklund, A., et al. 2017. Limited evidence on the effectiveness of interventions to reduce livestock predation by large carnivores. Scientific Reports 7:2097.

Espuno, N., et al. 2004. Heterogeneous response to preventive sheep husbandry during wolf recolonization of the French Alps. Wildlife Society Bulletin 32:1195-1208.

Franklin, W., and K. Powell. 2006. Guard llamas: A part of integrated sheep protection. Ames: Iowa Cooperative Extension.

Gates, N., et al. 1978. Development and evolution of anti-coyote electric fencing. Journal of Range Management 31(2): 151-153.

Gehring, T., et al. 2010. Utility of livestock-protection dogs for deterring wildlife from cattle farmers. USDA National Wildlife Research Center Staff Publications 1344.

2011. Good fences make good neighbors: Implementation of electric fencing for establishing effective livestockprotection dogs. Human-Wildlife Interactions 5(1): 106-111.

Knowlton, F., et al. 1999. Coyote depredation control: An interface between biology and management. Journal of Range Management 52:398-412. 
Lance, N., et al. 2010. Biological, technical, and social aspects of applying electrified fladry for livestock protection from wolves (Canis lupus). Wildlife Research 37:708-714.

Linhart, S. 1984. Efficacy of light and sound stimuli for reducing coyote predation upon pastured sheep. Protection Ecology 6:75-84.

Linhart S., et al. 1992. Electronic frightening devices for reducing coyote predation on domestic sheep: Efficacy under range conditions and operational use. In J. Borrecco and R. Marsh, eds., Proceedings of the 15th Vertebrate Pest Conference. Davis: Universitiy of California, Davis. 386-392.

Matchett, M., et al. 2013. Efficacy of electronet fencing for excluding coyotes: A case study for enhancing production of black-footed ferrets. USDA National Wildlife Research Center Staff Publications Paper 1522.

McInturff, A., et al. 2016. Preliminary FoxLight report. Hopland, CA: Univesity of California Cooperative Extension Hopland Research and Extension Center.

Miller, J., et al. 2016. Effectiveness of contemporary techniques for reducing livestock depredations by large carnivores. Wildlife Society Bulletin 40(4): 806-815.

Musiani, M., et al. 2003. Wolf depredation and the use of fladry barriers to protect livestock in western North America. Conservation Biology 17(6): 1538-1547.

Naughton-Treves, L., et al. 2003. Paying for tolerance: Rural citizens' attitudes toward wolf depredation and compensation. Conservation Biology 17(6): 1500-1511.

Stone, R. 2015. Farm fencing systems. OMAFRA Fact Sheet 08-035. Guelph, ON: Ontario Minstry of Agriculture, Food, and Rural Affairs.

Parks, M. 2015. Participant perceptions of range rider programs used to mitigate wolf-livestock conflicts in the western United States. Master's thesis. Logan: Utah State University All Graduate Theses and Dissertations 4444.
Parks, M., and T. Messmer. 2016. Participant perceptions of range rider programs operating to mitigate wolf-livestock conflicts in the western United States. Wildlife Society Bulletin (40)3: 514-524.

Ramler, J., et al. 2014. Crying wolf? A spatial analysis of wolf location and depredations on calf weight. American Journal of Agricultural Economics 96(3): 631-656.

Shivik, J. 2004. Non-lethal alternatives for predation management. Sheep and Goat Research Journal 19: 64-71.

Shivik, J., and D. Martin. 2001. Aversive and disruptive stimulus applications for managing predation. In M. C. Brittingham, J. Kays, and R. McPeake, eds., The 9th Wildlife Damage Management Conference Proceedings. Bethesda, MD: The Wildlife Society. 111-119.

Stone, S., et al. 2017. Adaptive use of nonlethal strategies for minimizing wolf-sheep conflict in Idaho. Journal of Mammalogy 98(1): 33-44.

Thompson, B. 1976. Evaluation of wire fences for control of coyote depredations. Master's thesis, Oregon State University.

Treves, A., and K. Ullas Karanth. 2003. Human-carnivore conflict and perspectives on carnivore management worldwide. Conservation Biology 17(6): 1491-1499.

USDA-APHIS (U.S. Department of Agriculture Animal and Plant Health Inspection Service) Veterinary Services. 2012. Cattle and calves predator death loss in the United States, 2010. Fort Collins, CO: USDA-APHIS.

2014. USDA expands research on larger dog breeds for use in livestock protection. Fort Collins, CO: USDA-APHIS.

2015. Sheep and lamb predator and nonpredator death loss in the United States, 2015. Fort Collins, CO: USDA-APHS.

2016. Cattle and calves predator death loss in the United States, 2016. Fort Collins, CO: USDA-APHS. 
USDA-APHIS Wildlife Services. 2010. Livestock protection dogs. USDA website, https://www.aphis.usda.gov/publications/ wildlife_damage/content/printable_version/fs_livestock_ protection.pdf.

VanBommel, L., and C. Johnson. 2012. Good dog! Using livestock guardian dogs to protect livestock from predators in Australia's extensive grazing systems. Wildlife Research 39:220-229.

Wade, D. 1982. The use of fences for predator damage control. Proceedings of the 10th Vertebrate Pest Conference. Paper 47.

Wagner, K., and M. Conover. 1999. Effect of preventive coyote hunting on sheep losses to coyote predation. Journal of Wildlife Management 63(2): 606-612.

Walton, M., and C. Field. 1989. Use of donkeys to guard sheep and goats in Texas. In S. Craven, ed., Proceedings of the 4th Eastern Wildlife Damage Control Conference. Milwaukee: Wisconsin Department of Natural Resources.

Webber, B., et al. 2015. Movements of domestic sheep in the presence of livestock guardian dogs. Sheep and Goat Research Journal 30:18-23.

Wielgus, R., and K. Peebles. 2014. Effects of wolf mortality on livestock depredations. PLoS ONE 9(12): e113505.

Wilbanks, C. 1995. Alternative methods of predator control. In Coyotes in the Southwest: A Compendium of our Knowledge. Paper 5. San Angelo, TX: Texas Parks and Wildlife Department.

Young, J., et al. 2011. Is wildlife going to the dogs? Impacts of feral and free-roaming dogs on wildlife populations. BioScience 61(2): 125-132.

2015a. Evaluating fladry designs to improve utility as a nonlethal management tool to reduce livestock depredation. Wildlife Society Bulletin 39(2): 429-433.

. 2015b. Human-carnivore interactions: Lessons learned from communities in the American West. Human Dimensions of Wildlife 20:349366.

\section{FOR FURTHER INFORMATION}

To order or obtain ANR publications and other products, visit the ANR

Communication Services online catalog at http://anrcatalog.ucanr.edu/ or phone 1-800-994-8849. You can also place orders by mail or request a printed catalog of our products from

University of California

Agriculture and Natural Resources

Communication Services

2801 Second Street

Davis, CA 95618

Telephone 1-800-994-8849

E-mail: anrcatalog@ucanr.edu

(c)2018 The Regents of the University of California. This work is licensed under the Creative Commons Attribution-NonCommercial-NoDerivatives 4.0 International License. To view a copy of this license, visit http://creativecommons.org/licenses/by-ncnd/4.0/ or send a letter to Creative Commons, PO Box 1866, Mountain View, CA 94042, USA.

Publication 8598

ISBN-13: 978-1-62711-028-0

The University of California, Division of Agriculture and Natural Resources (UC ANR) prohibits discrimination against or harassment of any person in any of its programs or activities on the basis of race, color, national origin, religion, sex, gender, gender expression, gender identity, pregnancy (which includes pregnancy, childbirth, and medical conditions related to pregnancy or childbirth), physical or mental disability, medical condition (cancer-related or genetic characteristics), genetic information (including family medical history), ancestry, marital status, age, sexual orientation, citizenship, status as a protected veteran or service in the uniformed services (as defined by the Uniformed Services Employment and Reemployment Rights Act of 1994 [USERRA]), as well as state military and naval service.

UC ANR policy prohibits retaliation against any employee or person in any of its programs or activities for bringing a complaint of discrimination or harassment. UC ANR policy also prohibits retaliation against a person who assists someone with a complaint of discrimination or harassment, or participates in any manner in an investigation or resolution of a complaint of discrimination or harassment. Retaliation includes threats, intimidation, reprisals, and/or adverse actions related to any of its programs or activities.

UC ANR is an Equal Opportunity/Affirmative Action Employer. All qualified applicants will receive consideration for employment and/or participation in any of its programs or activities without regard to race, color, religion, sex, national origin, disability, age or protected veteran status. 
University policy is intended to be consistent with the provisions of applicable State and Federal laws.

Inquiries regarding the University's equal employment opportunity policies may be directed to: John Sims, Affirmative Action Contact and Title IX Officer, University of California, Agriculture and Natural Resources, 2801 Second Street, Davis, CA 95618, (530) 750-1397. Email: jsims@ucanr.edu. Website: http://ucanr.edu/sites/anrstaff/Diversity/Affirmative_ Action/

To simplify information, trade names of products have been used. No endorsement of named or illustrated products is intended, nor is criticism implied of similar products that are not mentioned or illustrated.

An electronic copy of this publication can be found at the ANR Communication Services catalog website, http://anrcatalog.ucanr.edu/.

UC This publication has been anonymously peer reviewed for technical accuracy

PEER by University of California scientists and other qualified professionals. This review process was managed by ANR Associate Editor for Animal, Avian, and Veterinary Sciences Julie Finzel.

web-1/18-SB/CR 